\title{
Visuospatial Memory Improvement after Gamma Ventral Capsulotomy in Treatment Refractory Obsessive-Compulsive Disorder Patients
}

\author{
Marcelo C Batistuzzo*,I, Marcelo Q Hoexter', Anita Taub', André F Gentil', Raony CC Cesar', \\ Marinês A Joaquim', Carina Chaubet D'Alcante', Nicole C McLaughlin², Miguel M Canteras', Roseli G Shavitt', \\ Cary R Savage ${ }^{4}$, Benjamin D Greenberg ${ }^{2}$, Georg Norén ${ }^{5}$, Eurípedes C Miguel' and Antonio C Lopes' \\ 'Department \& Institute of Psychiatry, School of Medicine, University of São Paulo, São Paulo, Brazil; 'Department of Psychiatry and Behavioral \\ Sciences, Butler Hospital and Brown Medical School, Providence, RI, USA; 'Institute of Neurological Radiosurgery-Hospital Santa Paula, São Paulo, \\ Brazil; ${ }^{4}$ Center for Health Behavior Neuroscience, University of Kansas Medical Center, Kansas City, KS, USA; ${ }^{5}$ Department of Neurosurgery, The \\ Warren Alpert Medical School of Brown University, Providence, RI, USA
}

\begin{abstract}
Gamma ventral capsulotomy (GVC) radiosurgery is intended to minimize side effects while maintaining the efficacy of traditional thermocoagulation techniques for the treatment of refractory obsessive-compulsive disorder (OCD). Neuropsychological outcomes are not clear based on previous studies and, therefore, we investigated the effects of GVC on cognitive and motor performance. A doubleblind, randomized controlled trial (RCT) was conducted with 16 refractory OCD patients allocated to active treatment $(n=8)$ and sham $(n=8)$ groups. A comprehensive neuropsychological evaluation including intellectual functioning, attention, verbal and visuospatial learning and memory, visuospatial perception, inhibitory control, cognitive flexibility, and motor functioning was applied at baseline and one year after the procedure. Secondary analysis included all operated patients: eight from the active group, four from the sham group who were submitted to surgery after blind was broken, and five patients from a previous open pilot study $(n=5)$, totaling 17 patients. In the RCT, visuospatial memory (VSM) performance significantly improved in the active group after GVC $(p=0.008)$, and remained stable in the sham group. Considering all patients operated, there was no decline in cognitive or motor functioning after one year of follow-up. Our initial results after I year of follow-up suggests that GVC not only is a safe procedure in terms of neuropsychological functioning but in fact may actually improve certain neuropsychological domains, particularly VSM performance, in treatment refractory OCD patients.

Neuropsychopharmacology (20I5) 40, I837-I845; doi:I0.I038/npp.20I5.33; published online 4 March 2015
\end{abstract}

\section{INTRODUCTION}

Obsessive-compulsive disorder (OCD) is a debilitating condition with a lifetime prevalence between 2 and 3\% (Andrade et al, 2012; Ruscio et al, 2010). Clinical trials have established the use of selective serotonin reuptake inhibitors and/or cognitive behavioral therapy as first-line treatment options (Belotto-Silva et al, 2012). Unfortunately, up to $10 \%$ of patients remain refractory to all conventional treatments, including augmentation strategies (Bloch et al, 2006). Anterior capsulotomy (AC), a neurosurgical intervention that acts by disrupting white matter tracts of the corticostriatal-pallido-thalamic-cortical circuitry (hypothesized to be dysfunctional in OCD), has been successfully employed in carefully selected cases (Lopes et al, 2004; Rauch et al, 1994;

\footnotetext{
*Correspondence: Dr MC Batistuzzo, Department \& Institute of Psychiatry, School of Medicine, University of São Paulo, R. Dr Ovídio Pires de Campos, 785, $3^{\circ}$ andar, sala 9, São Paulo 0 1060-970, Brazil, Tel: +55 || 266 | 7267, E-mail: marcelobatistuzzo@gmail.com Received I 4 November 20 I4; revised 26 December 20 I4; accepted II January 2015; accepted article preview online 3 February 2015
}

Rück et al, 2008). Specifically, AC by thermocoagulation and gamma-knife radiosurgery (Gamma ventral capsulotomy, GVC) have demonstrated comparable efficacy in reducing obsessive-compulsive symptoms (OCS), although there are no studies directly comparing these techniques (Fodstad et al, 1982; Kondziolka et al, 2011; Lopes et al, 2004, 2009; Miguel et al, 2004; Rück et al, 2008). However, the safety profile of both surgical methods remain less clear, in particular regarding post-operative cognitive performance, with only a few studies investigating neuropsychological outcomes (Csigó et al, 2010; Fodstad et al, 1982; Nyman and Andreewitch, 2001; Nyman and Mindus, 1995; Rück et al, 2008; Taub et al, 2009).

The available literature reports stability of intellectual functioning (Csigó et al, 2010; Nyman and Andreewitch, 2001; Taub et al, 2009), but also development of verbal memory deficits (Binder and Iskandar, 2000) and executive dysfunctions (Nyman and Mindus, 1995) after AC. Longterm follow-up results are also inconsistent: Rück et al (2008) reported persistent mild deficits in executive functions eleven years after AC using both surgical techniques, whereas 
Nyman and Andreewitch, 2001; reported improvement in neuropsychological performance 7 years after GVC and Csigó et al (2010) reported similar results two years after thermocapsulotomy. These improvements were found in neuropsychological domains such as intellectual functioning (IQ), planning, verbal fluency, inhibitory control, and decision making.

It is difficult to establish the neuropsychological consequences of $\mathrm{AC}$ given that most studies comprised small groups of patients in open-label, uncontrolled designs (Csigó et al, 2010; Nyman and Andreewitch, 2001; Nyman and Mindus, 1995; Rück et al, 2008; Taub et al, 2009). Moreover, it is unclear whether changes on neuropsychological measures can be attributed to the neurosurgical procedures per se, are secondary to OCS improvement, or are practicerelated improvements following repeated neuropsychological testing. In order to better address these limitations, we conducted a longitudinal neuropsychological investigation in refractory OCD patients during a double-blind, placebocontrolled, randomized GVC trial (RCT). The efficacy and general safety of this study has been previously published by our group (Lopes et al, 2014).

Our main objective was to investigate the effects of GVC on cognitive and motor performance in both trial groups. Also based on previous reports that neurosurgical ablative procedures can be associated with cognitive adverse events (Binder and Iskandar, 2000; Nyman and Mindus, 1995; Rück et al, 2008), our secondary objective was to evaluate the neuropsychological safety of GVC by analyzing the outcome of all patients operated during the pilot study (Taub et al, 2009) and both blind and open trial phases. We hypothesized that cognitive and motor performance would improve 1 year after GVC while remaining stable in the control group. Finally, we expected that GVC would not cause severe impairments on cognitive or motor performance when considering all operated patients.

\section{MATERIALS AND METHODS}

\section{Ethical Aspects}

This study was approved by the institutional review board of the General Hospital of the University of São Paulo Medical School (USPMS) and by the Brazilian National Commission of Research Ethics. All patients signed informed consent forms and all procedures were in accordance with rigorous psychiatric surgery guidelines previously published by our group (Miguel et al, 2004).

\section{Subjects and Study Design}

The eligibility of 87 OCD patients was assessed at the USPMS OCD Spectrum Clinic, a tertiary referral center for nationwide highly refractory cases. Sixty-six subjects did not meet our selection criteria, mostly due to other comorbid diagnoses, intellectual deficiency, or insufficient refractoriness status (Lopes et al, 2014). Twenty-one patients were considered eligible: the first five were enrolled in an open pilot study (Lopes et al, 2009; Taub et al, 2009) and the remaining 16 participated in the RCT (refer to Lopes et al (2014) for a detailed description of study subjects, study design, randomization procedures, consort diagram, and methods of sham surgery. Trial registration: www.clinical trials.gov identifier NCT01004302).

Patients participating in the RCT were randomized into two groups: active treatment (ATa, patients who received true GVC, $n=8$ ), and sham (ST, $n=8$; Figure 1a). Patients and examiners remained blinded for the first year of followup. This intended to evaluate the long-term clinical efficacy of the procedure, as well as to measure the neuropsychological effects, minimizing test-retest related issues. When the blind phase was completed after 1 year, patients from the ST group were offered a true GVC procedure, and four of these eight patients were then operated ( $\mathrm{ATb}, n=4$; Figure $1 \mathrm{~b}$ ).

\section{GVC Procedure}

A detailed description of the gamma-knife-based GVC technique has been previously published (Lopes et al, 2009, 2014). In short, GVC procedures consisted of bilateral double lesions at the ventral border of the anterior limb of the internal capsule (7-10 $\mathrm{mm}$ rostral to the posterior edge of the anterior commissure-Supplementary Figure S1). Targets received the intended volume of necrosis defined by the $50 \%$ isodose line, with a maximum dose of $180 \mathrm{~Gy}$ at the $100 \%$ point, with 4-mm collimators. Calculations for each procedure were performed by an on-site neurosurgeon (MMC) and two psychiatrists (ACL and ECM) and further reviewed remotely by a neurosurgeon (GN) and a psychiatrist (BDG), from Brown University, all authors of the present study.




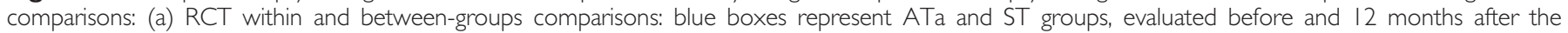

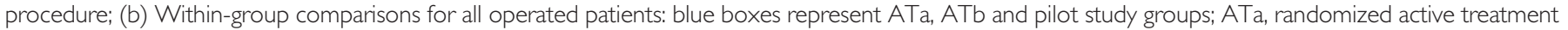

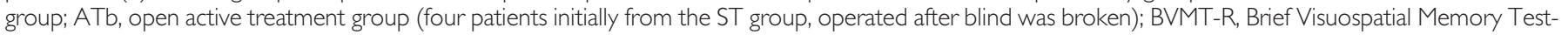

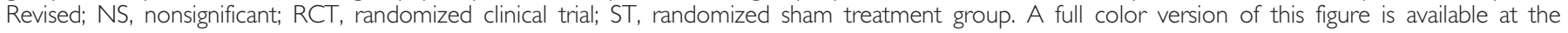
Neuropsychopharmacology journal online. 


\section{Psychiatric Evaluation}

Psychiatric diagnosis were made by two psychiatrists (ACL and ECM) using the Structured Clinical Interview for DSM-IV Diagnoses. OCD severity was accessed longitudinally by Y-BOCS scores, whereas depression and anxiety symptoms were measured by Beck Depression and Beck Anxiety Inventories (BDI and BAI, respectively; Beck et al, 1961, 1988). Patients were considered responders if $35 \%$ or more reduction of baseline Y-BOCS scores was achieved after GVC, with Clinical Global Impression improvement scores of 1 ('much improved') or 2 ('improved'; Guy, 1976).

\section{Neuropsychological Assessment}

All patients underwent a comprehensive neuropsychological evaluation with emphasis in memory and executive functions, known to be deficient in OCD. The following domains were assessed: intellectual functioning, cognitive screening, attention, language, verbal and VSM, spatial perception (visuospatial abilities), executive functions (cognitive flexibility), and motor functioning. Tests and their respective function domains are presented in Table 1 and in the online Supplement.

Neuropsychological assessments were performed by trained evaluators (MCB and CCD) in a single interview lasting up to $3 \mathrm{~h}$, depending on the patient's performance and symptom severity. Short break intervals were allowed as long as they did not disturb the evaluation (mostly delayed recall). Patients were assessed 1 week before GVC (true or sham) and re-evaluated after 1 year, before the blind was broken. Patients from the ATb group (originally from the sham group but later submitted to a true GVC) also received a third evaluation, 1 year after the final procedure (Figure 1b).

\section{Statistical Analysis}

Statistical analyses were conducted with the PASW Statistics, version 18 (2009) and the software R, version 2.14.1 (2012). The Kruskal-Wallis nonparametric test was used for between-group comparisons of demographic and clinical variables. Neuropsychological comparisons in the RCT (ATa vs ST) were conducted with the nonparametric MannWhitney $U$-test, and the Wilcoxon signed-rank test was used for within group comparisons (pre $v s$ post surgery). Delta scores (ie, pre minus post surgery) were used in nonparametric multivariate analysis of variance (NP-MANOVA) to test the interaction effect group $v s$ time for neuropsychological variables (Anderson, 2001). This technique provides a measure of effect size ( $F^{\star}$ value) similar to the parametric MANOVA's (F value), and it was intended to control for type I errors. Dependent variables were clustered for each NP-MANOVA, according to neuropsychological domains: intellectual functioning, attention, verbal memory, VSM, executive function (cognitive flexibility), spatial perception, and motor functioning (Table 2). Post hoc nonparametric repeated measures analysis of variance (NP-RM-ANOVA), corrected for Bonferroni's multiple comparisons, were also conducted (Singer et al, 2004).

Secondary analysis merged data from all operated patients (pilot study $(n=5), \mathrm{ATa}(n=8)$, and ATb groups $(n=4)$ Figure 1) and within-group comparisons (pre $v s$ post) were conducted with the nonparametric Wilcoxon signed-rank test for two related samples.

Finally, the effect of clinical symptomatology changes on neuropsychological performance was analyzed using Spearman's correlations to compare delta scores from Y-BOCS, $\mathrm{BDI}$, and BAI with neuropsychological variables. This was conducted separately for each RCT group and for all operated patients.

Analyses were based on raw scores, with the exception of IQ values. We adopted a two-tailed alpha level of significance of 0.05 and all statistical tests were based on exact significance (more conservative and appropriate to use in small samples).

\section{RESULTS}

\section{Baseline Measures}

Patients from the pilot group did not differ from the RCT groups regarding demographic and clinical data before surgery (Table 3). Patients from the ATa and ST groups were also similar in terms of age, gender, handedness, years of education, OCS severity, years of illness, IQ, depression, and anxiety symptoms (Table 3) and there were no differences in neuropsychological variables (Supplementary Table S1).

\section{Treatment Outcomes}

Randomized clinical trial. Three patients from the ATa group (37.5\%) and none from the ST group were responders after the blind phase (Table 2). Consistent reductions on Y-BOCS scores were observed only in the ATa group (38.4\%, $p$-value $=0.008, Z=2.5$, Wilcoxon/Exact). There were no significant changes in depression and anxiety symptoms for ATa patients along the blind phase, whereas ST patients improved from their depressive symptoms after sham treatment $(46 \%, p$-value $=0.008, Z=2.5$, Wilcoxon/Exact, Table 3).

All patients treated with GVC. One patient from the ATb group (25\%) and two patients from the pilot study (40\%) were classified as responders after 1 year of follow-up. Considering all operated patients (ATa, Atb, and pilot groups), six out of 17 patients (35\%) were responders after 1 year, with significant reductions in Y-BOCS $(35.8 \%$, $p$-value $=0.001, Z=3.1)$ and BAI $(37.4 \%, p$-value $=0.007$, $Z=2.6)$, but not in BDI scores $(24.4 \%$, $p$-value $=0.123$; Table 3).

\section{Neuropsychological Outcomes in the RCT}

ATa patients showed improved performance on measures of VSM when compared with ST patients after 1 year of followup, with significant group $v s$ time interactions in the VSM NP-MANOVA ( $p$-value $=0.008 ; \mathrm{F}^{*}$ value $=6.1$ ). Raw scores from four dependent variables were used in this analyses: (1) Brief Visuospatial Memory Test-Revised (BVMT-R) immediate total recall; (2) BVMT-R delayed recall; (3) BVMT-R discrimination index (a recognition score); and (4) ReyOsterrieth Complex Figure Test (ROCF) delayed recall (Table 2). NP-RM-ANOVA post hoc analysis found group 
Table I Neuropsychological Domains, Functions and Tests Employed in the Study

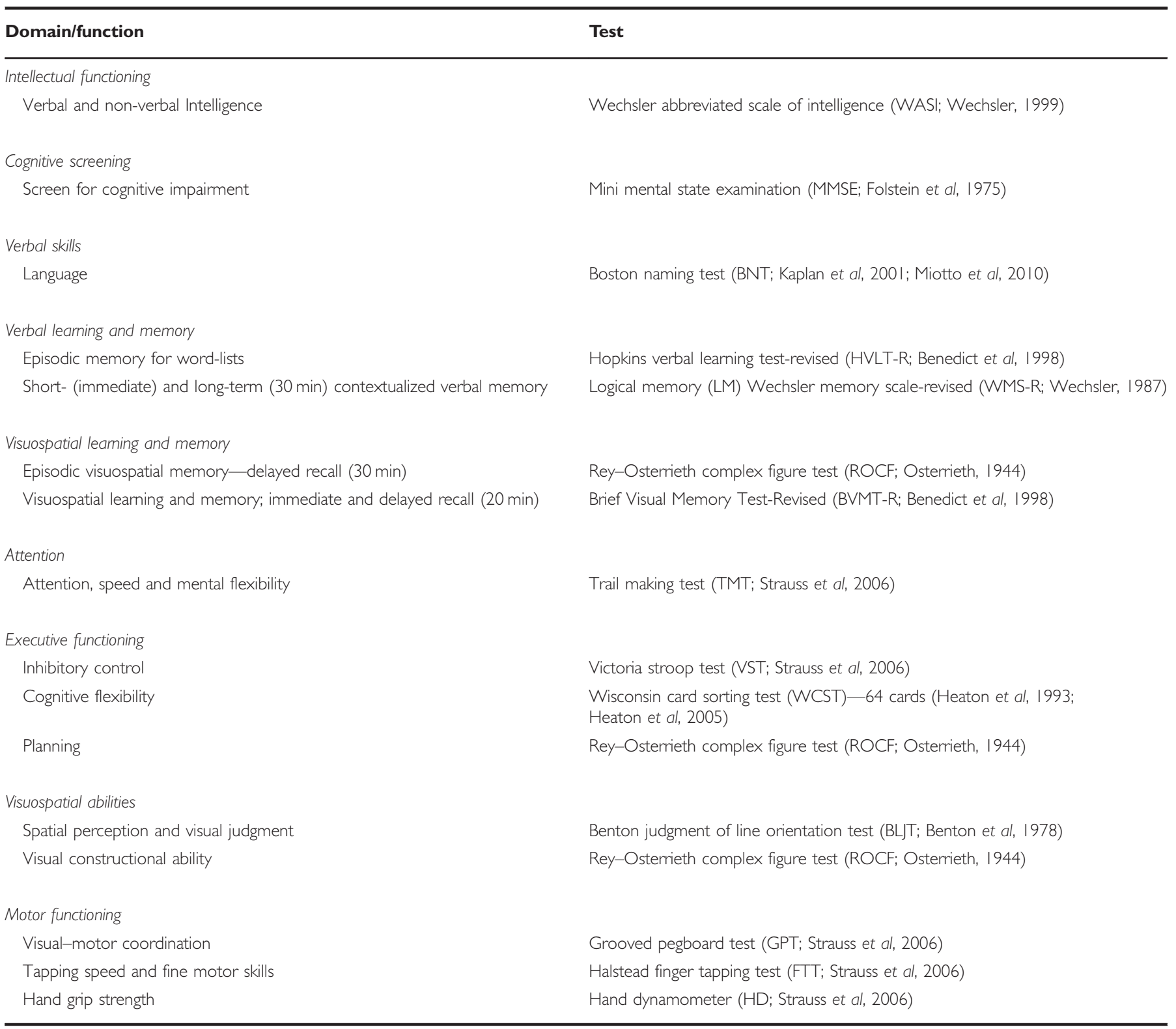

vs time interaction effects for the BVMT-R immediate total recall and ROCF delayed recall (Figure 2 and Table 2). Significant effects were not found in other cognitive domains (Table 2).

\section{Neuropsychological Outcomes for all Patients Treated with GVC}

Considering the 17 patients treated with GVC, within-group comparisons revealed improvement in several neuropsychological domains 1 year after the procedure: vocabulary $(p$-value $=0.027)$, performance IQ $(p$-value $=0.036)$, total IQ $(p$-value $=0.022)$, ROCF delayed recall $(p$-value $=0.017)$, Grooved Pegboard Test dominant-hand time $(p$-value $=$ 0.042 ), Hand Dynamometer nondominant-hand ( $p$-value $=$ 0.040), Wisconsin Card Sorting Test (WCST) correct responses $(p$-value $=0.049)$, and Trail A $(p$-value $=0.034$;
Supplementary Figure S2 and Supplementary Table S2). Although there were individual variations during the course of the follow-up, there was not a pattern of decreased neuropsychological performance for any patient, and ultimately there were no adverse changes in any neuropsychological domain 1 year after surgery.

\section{Neuropsychological Changes and Symptom Improvement}

Measures of clinical symptomatology based on Y-BOCS, $\mathrm{BDI}$, and BAI scores did not significantly correlate with neuropsychological changes in the analyses of RCT groups, and the same was found for the secondary analysis (considering all operated patients). 
Table 2 Clusters of Functions and the Respective Tests Enrolled in Each NP-MANOVA for Difference Within Performances



Abbreviations: NP-MANOVA, nonparametric multivariate analysis of variance; NP-RM-ANOVA, nonparametric repeated measures analysis of variance.

Post hoc analyses are indicated by NP-RM-ANOVA.

a Patients submitted to ATa improved after the procedure in comparison with ST, in bold the statistically significant comparisons considering a Bonferroni's correction $p$-value of 0.0125 .

${ }^{b} \mathrm{QW}$ is a measure of effect size similar to the $\mathrm{F}$ values of parametric ANOVA.

\section{DISCUSSION}

To our knowledge, this is the first RCT of an ablative surgical intervention for refractory OCD to have assessed neuropsychological functions, providing an opportunity to observe how patients fared without true surgery, controlling for time and practice effects. Results from the RCT suggests that GVC significantly improved VSM in patients actively treated (ATa group) when compared with the sham group (ST). Considering all patients who underwent the procedure (ATa, ATb, and pilot), improvements were observed on the following neuropsychological functions: vocabulary, intelligence, VSM delayed recall, motor performance, attention, and executive functioning. Therefore, in our sample, GVC not only showed efficacy in reducing OCS in treatment refractory OCD patients, but was also safe from a neuropsychological perspective.

Several studies have identified VSM as a specific and central neuropsychological deficit in OCD (Bloch et al, 2011; Grisham et al, 2009; Kuelz et al, 2004, 2006; Kim et al, 2002; Penadés et al, 2005; Purcell et al, 1998; Rao et al, 2008; Segalàs et al, 2008; Shin et al, 2013). Cross-sectional studies have shown that OCD patients present difficulties in VSM when compared with healthy controls (Kuelz et al, 2004; Purcell et al, 1998; Rao et al, 2008; Savage et al, 1999), and longitudinal studies indicate the presence of visuospatial deficits even before the onset of symptoms (Bloch et al, 2011; Grisham et al, 2009). Moreover, the improvement of VSM has been described after successful treatment for OCD (Kim et al, 2002). Kuelz et al (2008) found that major responders to treatment improved significantly more than minor responders on the ROCF immediate and delayed recall. Indeed, a recent meta-analysis on neuropsychological data and OCD has indicated that VSM is the most consistently cognitive improvement in OCD (ie, VSM presented the largest effect size among all neuropsychological domains; Shin et al, 2013).

Neuropsychological functioning has been previously assessed in patients with OCD following AC using thermocoagulation. Nyman and Mindus (1995) found that three out of five patients presented more perseverative responses in the WCST (a mental flexibility task), 1 year after surgery. Rück et al (2008) included two additional patients in this sample and reported mental flexibility deficits in six out of seven patients after 11 years of follow-up. Contrary to these findings, within-group comparisons in our study demonstrated improved WCST performance in the ATa group (Supplementary Table S1). One possible explanation could be that the smaller radiosurgical lesions employed in our study (Lopes et al, 2004, 2009) in comparison with the previous literature (Nyman and Mindus, 1995; Rück et al, 2003,2008 ) could cause less disruption in the neural circuitry responsible for these measures of neuropsychological functioning.

It has been previously postulated that neurosurgery for psychiatric disorders can modulate neuropsychological 
Table 3 Demographic Characteristics, Clinical Scores and Treatment Outcomes for Each Study Group

\begin{tabular}{|c|c|c|c|c|c|c|}
\hline & $\begin{array}{c}\text { Pilot } \\
(N=5) \\
\text { mean }(S D)[\text { range] }\end{array}$ & $\begin{array}{c}\text { Sham group } \\
\text { ST }(N=8) \\
\text { mean }(S D) \text { [range] }\end{array}$ & $\begin{array}{c}\text { Active treatment } \\
\text { ATa }(N=8) \\
\text { mean }(\mathrm{SD})[\text { range }]\end{array}$ & $\begin{array}{c}\text { Exact } \\
p \text {-value }{ }^{a}\end{array}$ & $\begin{array}{c}\text { Open treatment } \\
\text { ATb }(N=4) \\
\text { mean (SD) [range] }\end{array}$ & $\begin{array}{c}\text { Pilot+ATa+ATb } \\
(N=I 7) \\
\text { mean (SD) [range] }\end{array}$ \\
\hline Handedness, right:left & $5: 0$ & $7: 1$ & $7: 1$ & - & $4: 0$ & $16: 1$ \\
\hline Age & 35 (I I.I) [23-49] & $34.1(10.1)$ [24-53] & 32.1 (I0.6) [2I-55] & 0.796 & 38.0 (I I.8) [26-54] & $34.4(10.6)[2 \mid-55]$ \\
\hline $\begin{array}{l}\text { Illness duration after } \\
\text { first onset of OCS (years) }\end{array}$ & $25.0(12.9)[9-39]$ & $19.4(11.0)[10-40]$ & $20.3(13.8)[6-48]$ & 0.700 & $23.5(13.5)[12-40]$ & $22.4(12.8)[6-48]$ \\
\hline Responders & $2: 5$ & $0: 8$ & $3: 8$ & - & ।:4 & $6: 17$ \\
\hline Y-BOCS pre scores & $32.2(1.48)[30-34]$ & $34.8(4.0)[29-40]$ & 33.3 (2.8) [30-36] & 0.365 & $34.3(4.4)[30-40]$ & $32.9(2.6)[23-40]$ \\
\hline Y-BOCS post scores & $20.6(12.3)[10-40]$ & $31.9(4.1)[27-40]^{\mathrm{b}}$ & $20.9(11.0)[1-34]^{b}$ & 0.067 & $23.8(17.3)[0-40]$ & $21.4(11.7)[1-40]$ \\
\hline $\mathrm{BDI}$ percentage decrease & $45.1 \%$ & $46.0 \%$ & $21.5 \%$ & - & $4.4 \%$ & $24.4 \%$ \\
\hline BAl pre scores & $27.6(11.5)[17-45]$ & $19.3(15.3)[0-45]$ & $22.9(17.1)[3-60]$ & 0.542 & | $3.0(4.9)[7-19]$ & $21.9(13.9)[3-60]$ \\
\hline BAl post scores & $12.6(8.11)[2-24]$ & । I.0 (5.8) [3-19] & $13.4(10.5)[4-37]$ & 0.933 & $9.8(6.1)[3-17]$ & $10.8(8.2)[2-37]$ \\
\hline BAl percentage decrease & $71.3 \%$ & $30.8 \%$ & $22.4 \%$ & - & $25.0 \%$ & $37.4 \%$ \\
\hline Estimated IQ (WASI) & 93.0 (I3.5) [77-108] & $87.1(10.8)[7 \mid-103]$ & $90(15.4)[76-122]$ & 0.692 & $89.3(14.8)$ [77-109] & $90.7(13.8)[76-122]$ \\
\hline
\end{tabular}

Abbreviations: ATa, randomized active treatment group; ATb, open active treatment group (four patients initially from the ST group, operated after blind was broken); OBS, obsessive-compulsive symptoms; ST, randomized sham treatment group.

${ }^{a}$ Kruskal-Wallis test.

bStatistically significant difference (Mann-Whitney U-test) between ATa and ST groups ( $p$-value 0.019).

performance in different ways (Nyman and Andreewitch, 2001): (1) negatively impact performance by disrupting neural pathways; (2) positively impact cognitive functioning due to amelioration of symptoms; or (3) positively impact cognitive performance by interrupting abnormal circuits. The following discussion is based on these three assumptions: (1) the lack of long term neuropsychological deficits in our sample supports the view that the interruption of frontalstriatal neural pathways does not have a negative impact on neuropsychological performance; (2) we did not find correlations between measures of clinical symptoms and cognitive function (although both improved) in the RCT analysis or when considering all operated patients, indicating that the improvement on VSM occurred independently from psychopathological symptom reductions, although we could have been limited of statistical power for correlation analysis due to small sample sizes. Another explanation is that current clinical rating scales did not reliably characterize symptom changes in refractory OCD samples. Future measures based on the research domain criteria initiative may overcome this issue, focusing in biological markers rather than clinical symptomatology (Insel et al, 2010). Alternatively, it is also possible that symptom improvements, together with other aspects that interfere with patients' motivation or concentration, had a role in the post-operative neuropsychological evaluation; and (3) since the amelioration of neuropsychological functions in our patients submitted to surgery probably did not occur by chance, the third assumption possible interpretation seems to better explain our results. The interruption of hyperfunctional frontal-striatal circuits involved in the pathophysiology of OCD (Fodstad et al, 1982; Kondziolka et al, 2011; Lopes et al, 2009; Rück et al, 2008) could directly or indirectly lead to restorative changes in prefrontal cortex and therefore VSM pathways, restoring previous dysfunctional VSM circuits (Curtis, 2006; Figee et al, 2013).

Distinct cognitive domains assessed by VSM tests, including visual attention, spatial perception, visuomotor skills, and visuospatial organization, could have contributed to our overall findings. However, results from tests that specifically evaluated these functions (respectively the Trail Making Test, Benton Judgment of Line Orientation, Block Design test, and planning score of ROCF) did not show group $v s$ time interactions (ATa $v s \mathrm{ST}$, pre $v s$ post surgery), suggesting that our findings represent a primary improvement in VSM. Moreover, improvements in VSM were consistently obtained by two distinct and well-recognized VSM neuropsychological tests: BVMT-R and ROCF. Also, although we have searched for variables that could be responsible for the improvement of VSM in the ATa group, none of the following variables have influenced our results: gender, symptom severity, number of comorbidities, and number of previous complete treatments.

Group and individual analysis of results from our study showed no impairments in neuropsychological function for all the operated patients after 1 year of follow-up. In fact, neuropsychological improvements were observed in different domains like intelligence, attention, memory, motor 

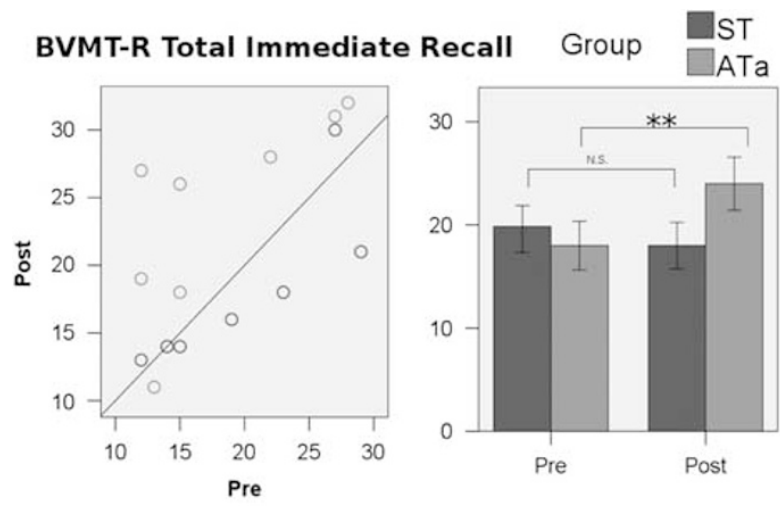

BVMT-R Delayed Recall
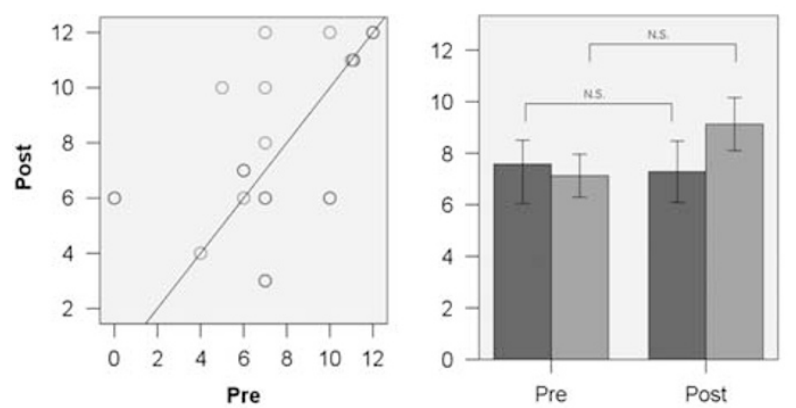

BVMT-R Discrimination Index


ROCF Delayed Recall


Figure 2 Interaction effects of four visuospatial memory tests (NPMANOVA). Statistically significant differences of within-group comparisons for the ATa group (green): $* p$-value $=0.016 / * *$-value $=0.008$. The error bars represent the 95\% confidence interval; ATa, randomized Active Treatment group (green); BVMT-R, Brief Visuospatial Memory Test-Revised; ROCF, Rey-Osterrieth complex figure; ST, sham treatment group (blue). A full color version of this figure is available at the Neuropsychopharmacology journal online. functions, and executive functions. Although this analysis had its limitations (eg, learning effects and different evaluations time points), it is still in accordance with a recent study by Csigó et al (2010) reporting improvement in five of ten neuropsychological domains in five refractory OCD patients submitted to traditional AC followed for 24 months.

Despite our results, caution should still be warranted for GVC. Given our very strict inclusion and exclusion criteria, our results may not be generalized. Also, 1 year of follow-up may be considered a relatively short period considering the risks of long-term complications of radiosurgery, and in fact one of our patients developed an asymptomatic radionecrotic cyst later in the follow-up, as previously reported (Lopes et al, 2014). Thus, other complications may develop over longer follow-up periods. Learning effects may also have occurred, although a 12-month interval between neuropsychological assessments seems reasonable. This could have been especially relevant for the analysis that combined all operated patients, as patients from the $\mathrm{ATb}$ group were evaluated three times (in the RCT learning effects were controlled by the study design). Finally, it was not possible to conclude if the observed improvement of VSM in the ATa group resulted directly from the surgical intervention, or was due to other factors such as improvement of motivational drive or represented just an epiphenomenon. In fact, it is unknown if VSM deficits are trait or state dependent in OCD, and a healthy control group could have helped to investigate if even with the observed improvement of neuropsychological functioning after surgery, patients would still have deficits when compared with healthy controls.

Despite these and other limitations, our study provides new evidence regarding the possible effects of GVC on cognitive and motor performance-there was a significant VSM improvement in the RCT treated group. Also, our analysis revealed that intellectual functioning, attention, memory, motor skills, and executive functioning improved in the group of patients that received GVC. Even if taken with caution (especially in the case of secondary analysis), these findings and the absence of significant cognitive deficits 1 year after surgery corroborates to previous reports by our group (Taub et al, 2009) and others (Csigó et al, 2010), regarding the potential benefit and neuropsychological safety of GVC for patients with refractory OCD.

\section{FUNDING AND DISCLOSURE}

The authors declare no conflict of interest.

\section{ACKNOWLEDGMENTS}

This work received financial support from the Foundation for the Support of Research in the State of São Paulo (FAPESP, Brazil) grants no. 2005/55628-08, 2008/10257-0, 2009/09949-8, 2011/21357-9 and no. 2011/51485-9) and from the National Council for Scientific and Technological Development (CNPq, Brazil, grant no. 302463/2011-9). Some results from this study have been previously presented in poster form at the 69th Meeting of the Society of Biological Psychiatry in New York, NY (2014). Clinical trial registration: Radiosurgical Treatment for Obsessive-Compulsive Disorder; ClinicalTrials.gov Identifier: NCT01004302. 


\section{REFERENCES}

Anderson MJ (2001). A new method for non-parametric multivariate analysis of variance. Austral Ecol 26: 32-46.

Andrade L, Wang Y, Andreoni S (2012). Mental disorders in megacities: findings from the Sao Paulo megacity mental health survey, Brazil. PLoS One 7: e31879.

Beck AT, Epstein N, Brown G, Steer RA (1988). An inventory for measuring clinical anxiety: psychometric properties. J Consul Clin Psychol 56: 893-897.

Beck AT, Ward CH, Mendelson M, Mock J, Erbaugh J (1961). An inventory for measuring depression. Arch Gen Psychiatry 4: 561-571.

Belotto-Silva C, Diniz JB, Malavazzi DM, Valério C, Fossaluza V, Borcato $S$ et al (2012). Group cognitive-behavioral therapy versus selective serotonin reuptake inhibitors for obsessive-compulsive disorder: a practical clinical trial. J Anxiety Disord 26: 25-31.

Benedict RHB, Schretlen D, Groninger L, Brandt J (1998). Hopkins verbal learning test-revised: normative data and analysis of inter-form and test-retest reliability. Clin Neuropsychol 12: 43-55.

Benton AL, Varney NR, Hamsher KD (1978). Visuospatial judgment. A clinical test. Arch Neurol 35: 364-367.

Binder DK, Iskandar BJ (2000). Modern neurosurgery for psychiatric disorders. Neurosurgery 47: 9-21; discussion 21-3.

Bloch $\mathrm{MH}$, Landeros-Weisenberger A, Kelmendi B, Coric V, Bracken MB, Leckman JF (2006). A systematic review: antipsychotic augmentation with treatment refractory obsessivecompulsive disorder. Mol Psychiatry 11: 622-632.

Bloch MH, Sukhodolsky DG, Dombrowski Pa, Panza KE, Craiglow BG, Landeros-Weisenberger A et al (2011). Poor finemotor and visuospatial skills predict persistence of pediatric-onset obsessive-compulsive disorder into adulthood. J Child Psychol Psychiatry 52: 974-983.

Csigó K, Harsányi A, Demeter G, Rajkai C, Németh A, Racsmány M (2010). Long-term follow-up of patients with obsessive-compulsive disorder treated by anterior capsulotomy: a neuropsychological study. J Affect Disord 126: 198-205.

Curtis CE (2006). Prefrontal and parietal contributions to spatial working memory. Neuroscience 139: 173-180.

Figee M, Luigjes J, Smolders R, Valencia-Alfonso C-E, van Wingen G, de Kwaasteniet B et al (2013). Deep brain stimulation restores frontostriatal network activity in obsessive-compulsive disorder. Nat Neurosci 16: 386-387.

Fodstad H, Strandman E, Karlsson B, West K (1982). Treatment of chronic obsessive compulsive states with stereotactic anterior capsulotomy or cingulotomy. Acta Neurochir (Wien) 62: 1-23.

Folstein MF, Folstein SE, McHugh PR (1975). 'Mini-mental state'. A practical method for grading the cognitive state of patients for the clinician. J Psychiatr Res 12: 189-198.

Grisham JR, Anderson TM, Poulton R, Moffitt TE, Andrews G (2009). Childhood neuropsychological deficits associated with adult obsessive-compulsive disorder. Br J Psychiatry 195: 138-141.

Guy W (1976). Assessment Manual for Psychopharmacology Revised. Clinical Global Impression Scale. Department of Health, Education and Welfare. Public Health Service, Alcohol, Drug Abuse, and Mental Health Administration: Rockville, MD, USA, pp 218-222.

Heaton RK, Chelune G, Talley J, Kay G, Curtiss G (1993). Wisconsin Card Sorting Test Manual-Revised and Expanded. Psychological Assessment Resourses Inc: Odessa, FL, USA.

Heaton RK, Chelune G, Talley J, Kay G, Curtiss G (2005). Teste Wisconsin de Classificação de Cartas: manual revisado e ampliado; adaptação e padronização brasileira Jurema Alcides Cunha et al. Casa do Psicólogo: São Paulo, Brazil.

Insel T, Cuthbert B, Garvey M, Heinssen R, Pine DS, Quinn K et al (2010). Research domain criteria (RDoC): toward a new classification framework for research on mental disorders. Am J Psychiatry 167: 748-751.

Kaplan E, Goodglass H, Weintraub S (2001). The Boston Naming Test, 2nd edn. Lippincott Williams \& Wilkins: Philadelphia, PA, USA.

Kim M-S, Park S-J, Shin MS, Kwon JS (2002). Neuropsychological profile in patients with obsessive-compulsive disorder over a period of 4-month treatment. J Psychiatr Res 36: 257-265.

Kondziolka D, Flickinger JC, Hudak R (2011). Results following gamma knife radiosurgical anterior capsulotomies for obsessive compulsive disorder. Neurosurgery 68: 28-32; discussion 23-3.

Kuelz AK, Hohagen F, Voderholzer U (2004). Neuropsychological performance in obsessive-compulsive disorder: a critical review. Biol Psychology 65: 185-236.

Kuelz AK, Riemann D, Halsband U, Vielhaber K, Unterrainer J, Kordon A et al (2006). Neuropsychological impairment in obsessive-compulsive disorder-improvement over the course of cognitive behavioral treatment. J Clin Exp Neuropsychol 28: 1273-1287.

Lopes AC, de Mathis ME, Canteras MM, Salvajoli JV, Del-porto JA, Miguel EC (2004). Update on neurosurgical treatment for obsessive compulsive disorder. Rev Bras Psiquiatr 26: 62-66.

Lopes AC, Greenberg BD, Norén G, Canteras MM, Busatto GF, de Mathis ME et al (2009). Treatment of resistant obsessivecompulsive disorder with ventral capsular/ventral striatal gamma capsulotomy: a pilot prospective study. J Neuropsychiatry Clin Neurosci 21: 381-392.

Lopes AC, Greenberg BD, Canteras MM, Batistuzzo MC, Hoexter MQ, Gentil AF et al (2014). Gamma ventral capsulotomy for obsessive-compulsive disorder: a double-blind, randomized controlled trial. JAMA Psychiatry 88: 177-182.

Miguel EC, Lopes AC, Guertzenstein EZ, Calazas MEB, Teixeira MJ, Brasil MA (2004). Guidelines for neurosurgery of severe psychiatric disorders in Brazil: a preliminary proposal. Rev Bras Psiquiatr 26: 8-9.

Miotto EC, Sato J, Lucia MCS, Camargo CHP, Scaff M (2010). Development of an adapted version of the Boston Naming Test for Portuguese speakers. Rev Bras Psiquiatr 32: 279-282.

Nyman H, Andreewitch S (2001). Executive and cognitive functions in patients with extreme obsessive-compulsive disorder treated by capsulotomy. Appl Neuropsychol 8: 91-98.

Nyman H, Mindus P (1995). Neuropsychological correlates of intractable anxiety disorder before and after capsulotomy. Acta Psychiatr Scand 91: 23-31.

Osterrieth P (1944). Le test de copie d'une figure complexe. Arch Psychol 30: 206-356.

Penadés R, Catalán R, Andrés S, Salamero M, Gastó C (2005). Executive function and nonverbal memory in obsessivecompulsive disorder. Psychiatry Res 133: 81-90.

Purcell R, Maruff P, Kyrios M, Pantelis C (1998). Cognitive deficits in obsessive-compulsive disorder on tests of frontal-striatal function. Biol Psychiatry 43: 348-357.

Rao NP, Reddy YCJ, Kumar KJ, Kandavel T, Chandrashekar CR (2008). Are neuropsychological deficits trait markers in OCD? Prog Neuropsychopharmacol Biol Psychiatry 32: 1574-1579.

Rauch SL, Jenike MA, Alpert NM, Baer L, Breiter HC, Savage CR et al (1994). Regional cerebral blood flow measured during symptom provocation in obsessive-compulsive disorder using oxygen 15-labeled carbon dioxide and positron emission tomography. Arch Gen Psychiatry 51: 62-70.

Rück C, Andréewitch S, Flyckt K, Edman G, Nyman H, Meyerson Ba et al (2003). Capsulotomy for refractory anxiety disorders: long-term follow-up of 26 patients. Am J Psychiatry 160: 513-521.

Rück C, Karlsson A, Steele JD, Edman G, Meyerson BA, Ericson K et al (2008). Capsulotomy for obsessive-compulsive disorder: long-term follow-up of 25 patients. Arch Gen Psychiatry 65: 914-921.

Ruscio AM, Stein DJ, Chiu WT, Kessler RC (2010). The epidemiology of obsessive-compulsive disorder in the National Comorbidity Survey Replication. Mol Psychiatry 15: 53-63. 
Savage CR, Baer L, Keuthen NJ, Brown HD, Rauch SL, Jenike MA (1999). Organizational strategies mediate nonverbal memory impairment in obsessive-compulsive disorder. Biol Psychiatry 45: 905-916.

Segalàs C, Alonso P, Labad J, Jaurrieta N, Real E, Jiménez S et al (2008). Verbal and nonverbal memory processing in patients with obsessive-compulsive disorder: its relationship to clinical variables. Neuropsychology 22: 262-272.

Shin NY, Lee TY, Kim E, Kwon JS (2013). Cognitive functioning in obsessive-compulsive disorder: a meta-analysis. Psychol Med 1-10.

Singer JM, Poleto FZ, Rosa P (2004). Parametric and nonparametric analyses of repeated ordinal categorical data. Biometric $J$ 46: 460-473.
Strauss E, Sherman E, Spreen O (2006). A compendium of neuropsychological tests: Administration, Norms, and Commentary. Oxford University Press: New York, NY, 1216.

Taub A, Lopes AC, Fuentes D, D'Alcante CC, de Mathis ME, Canteras MM et al (2009). Neuropsychological outcome of ventral capsular/ventral striatal gamma capsulotomy for refractory obsessive-compulsive disorder: a pilot study. J Neuropsychiatry Clin Neurosci 21: 393-397.

Wechsler D (1987). Manual for the Wechsler Memory ScaleRevised. The Psychological Corporation: San Antonio, TX, USA. Wechsler D (1999). Wechsler abbreviated scale of intelligence (WASI). The Psychological Corporation: San Antonio, TX, USA.

Supplementary Information accompanies the paper on the Neuropsychopharmacology website (http://www.nature.com/npp) 